\title{
A ECONOMIA ANTIGA, A MODERNIDADE E A RELAÇÃO OCIDENTE E ORIENTE: AS CONTRIBUIÇÕES DE KARL MARX E MAX WEBER
}

\author{
Alexandre Galvão Carvalho ${ }^{1}$
}

\section{Resumo}

Os trabalhos de Karl Marx (1818-1883) e Max Weber (1864-1920) sobre a economia e sociedade do mundo antigo inauguram uma nova perspectiva em relação aos economistas dos séculos XVIII e XIX e nos debates acerca da economia antiga travados na Alemanha no final do século XIX. Diferente dos economistas neoclássicos e dos modernistas e primitivistas, esses autores irão defender a tese de uma ruptura radical entre o mundo antigo e o moderno. Uma descontinuidade marcada, para Marx, pelo nascimento do sistema capitalista, e para Weber, do capitalismo moderno. Além dessa similaridade, esses pensadores reforçaram a visão eurocêntrica ao afirmarem que as raízes culturais e políticas do Ocidente moderno repousam na Antiguidade Clássica, reforçando uma tradição de pensamento de profundas clivagens entre as sociedades antigas do Oriente e as sociedades do mundo greco-romano, muito contestada na historiografia atual.

\section{Palavras-chave}

Karl Marx; Max Weber; Economia Antiga.

\footnotetext{
1 Professor Doutor, Universidade Estadual do Sudoeste da Bahia, Vitória da Conquista, Brasil. E-mail: galvaocarvalho@uol.com.br
} 


\begin{abstract}
The work of Karl Marx (1818-1883) and Max Weber (1864-1920) on the economy and society of the ancient world inaugurate a new perspective in relation to the economists of the 18th and 19th centuries and in debates about the old economy locked in Germany in the late 19th century. Different from neoclassical economists and the modernists and primitivism, these authors will defend the thesis of a radical break between the old world and the modern. A discontinuity marked, for Marx, the birth of the capitalist system, and for Weber, of modern capitalism. In addition to this similarity, these thinkers have reinforced the Eurocentric view by stating that the cultural and political roots of modern west lie in Classical Antiquity, reinforcing a tradition of thought of deep rifts between the ancient societies of the East and the societies of the Greco-Roman world, much contested in current historiography.
\end{abstract}

\title{
Keywords
}

Karl Marx; Max Weber; Ancient Economy. 


\section{Preâmbulo}

Para os neoclássicos como Adam Smith, Malthus e Steuart, a abordagem comparativa da análise econômica, com exemplos e textos clássicos, é marcada por uma ausência de qualquer conceito fundamental que distingue o mundo moderno em sua constituição econômica ou superior em suas qualidades. Suas explicações, permeadas de material histórico usado para enfatizar princípios econômicos gerais e a variabilidade do comportamento humano, geralmente, assumem uma continuidade e comparabilidade entre o passado e o presente. As distinções eram caraterizadas em termos de estágios de desenvolvimento econômico na história, pastoril para a agricultura e, em seguida, para o comércio.

No século XIX, os teóricos da economia política, como David Ricardo, estão mais preocupados em identificar leis econômicas e estruturas com base nos princípios lógicos, ao invés de produzi-las a partir da evidência empírica. Uma disciplina mais abstrata e dedutiva, concentrada nos assuntos puramente econômicos, na qual a história, junto com a antiguidade clássica, só era utilizada para mostrar a superioridade do conhecimento econômico moderno. Assim, a Antiguidade Clássica tinha pouco a oferecer ao pensamento econômico moderno, com poucos exemplos dignos de serem citados, como Aristóteles, um pioneiro da análise econômica "rudimentar".

O desprezo pela Antiguidade é explicável pela identificação de que os princípios e as leis que determinavam as operações da economia eram universalmente aplicáveis e identificáveis em qualquer contexto histórico passado. A análise histórica nada acrescentaria às tentativas de compreender a economia, podendo inclusive criar confusões por gerar inconsistências e sugerir que os princípios econômicos logicamente derivados poderiam ser rejeitados em favor das circunstancias contingenciais. Portanto, a modernidade não precisava ser analisada ou definida, posto que os princípios da economia política eram universais².

Os economistas alemães do século XIX rejeitaram essa perspectiva ahistórica da economia política clássica. A preferência pelos métodos históricos com o intuito de historicizar a economia política clássica constituiu o objetivo mais geral de pensadores alemães como Adam Müller, Friedrich List e F. K. Savigny. Seus trabalhos influenciaram os membros da Escola Histórica de Teoria Econômica que remonta à década de 1840, cujos primeiros representantes foram Wilhelm Roscher, Bruno

\footnotetext{
2 Para uma discussão mais detalhada do papel dos economistas clássicos em relação à antiguidade, ver MORLEY, N. The Great Transformation: Ancient and Modern Economics. In: Antiquity and Modernity. Oxford: Wiley-Blackwell, 2009.
} 
Hildebrand e Karl Knies e, posteriormente, Gustav von Schmoller, na década de 1870. Roscher defendeu um estudo comparativo de todos os povos, para discernir os traços semelhantes que poderiam se constituir em lei de desenvolvimento. Para estes autores, em uma perspectiva evolucionista e até próximo de Adam Smith, as sociedades pré-modernas já tinham alcançado níveis mais altos de desenvolvimento. Roscher e List caracterizaram as cidades gregas clássicas e, especialmente, o Império Romano, em termos muito mais positivos, com analogias entre o passado e o presente, assim como contrastes.

Essas ideias encontraram expressão nos trabalhos de historiadores econômicos, como Karl Bücher e historiadores da Antiguidade, como Theodor Mommsen. Entretanto, entre esses autores, a convergência era apenas em relação à importância dos fatores econômicos na análise do mundo antigo e da história como elemento a ser levado em consideração pela economia política, posto que Mommsen (1854: 368) identificou fatores econômicos na queda da República, em consequência da proeminência unilateral do capital na economia romana, inseparável dos males de um sistema capitalista que não podia deixar de aparecer, enquanto Karl Bücher defendeu, em seu ensaio Die Entstehung der Volkswirtschaft (As Origens da Economia Nacional), a descoberta de leis específicas para as sociedades pré-capitalistas, em uma perspectiva evolucionista, em contraponto à economia política clássica que utiliza categorias da economia nacional moderna em todas as épocas, baseada na troca de bens, ausente nas sociedades pré-capitalistas. Assim, para este autor, diferente de muitos historiadores da época, o mundo antigo era moldado pela economia doméstica fechada, sem trocas, pois a produção é pessoal e os bens são consumidos no mesmo local onde são produzidos.

A perspectiva de Bücher de que todo o mundo antigo era dominado pelo oikos, sem trocas, gerou uma forte polêmica com historiadores na Alemanha, como, por exemplo, Eduard Meyer, que contestou Bücher, afirmando que o mundo antigo apresentava uma economia completamente desenvolvida tanto no plano industrial quanto capitalista, com trocas e comércio. As diferenças eram muito mais de grau do que de natureza. Os debates entre Bücher e Meyer originaram a famosa contenda do oikos, do final do século XIX entre primitivistas, signatários de Bücher e modernistas, próximos da opinião de Meyer. Apesar dessas diferenças, tanto Bücher quanto Meyer, e seus sucessores, defenderam a existência de uma única continuidade entre o mundo antigo e o moderno. Para os primitivistas, uma continuidade linear, para os modernistas, cíclica. 


\section{A Descontinuidade entre o Antigo e o Moderno e a Importância do}

\section{Econômico}

Max Weber (1864-1920) iniciou sua carreira acadêmica desenvolvendo trabalhos de História Antiga. Mommsen o considerava como seu sucessor e o primeiro trabalho sobre o mundo antigo de Weber, Die römische Agrargeschichte (História Agrária Romana), de 1891, foi muito bem recebido pelos historiadores. Ao mesmo tempo, ele é considerado por muitos como o herdeiro mais ilustre da Escola Histórica de Teoria Econômica, tendo ocupado a cadeira de economia política em Heidelberg, no lugar de Karl Knies. Apesar das influências de Mommsen e da Escola Histórica de Teoria Econômica, em particular, a importância da história para a compreensão do desenvolvimento econômico das sociedades, Weber rompeu com a ideia de que, entre o mundo antigo e o moderno, não se deveria ressaltar as descontinuidades. Para ele, a questão das diferenças entre as sociedades pré-modernas e moderna era central em seu arcabouço teórico sobre a natureza e as origens do capitalismo, elemento central de suas pesquisas.

É nos trabalhos de Karl Marx (1818-1883) que repousa a influência maior dessa mudança de perspectiva, levada a cabo por Weber, em relação aos economistas e historiadores alemães, pois as mudanças do mundo moderno, com ressonâncias em todos os aspectos da vida humana, constituem-se em uma grande transformação para Marx, uma descontinuidade dramática no desenvolvimento histórico que separa o período moderno do antigo, estando a esfera econômica no centro de seus argumentos acerca das interpretações da natureza e do desenvolvimento da modernidade. Essa perspectiva comum é bem diversa dos escritos dos pensadores do século XVIII e XIX e dos economistas e historiadores alemães do século XIX, sendo Weber devedor de Marx por esta ruptura, tendo ambos, tomado o capitalismo como elemento central de suas pesquisas.

No entanto, se há convergência sobre a ruptura, a descontinuidade entre o mundo antigo e o moderno, as formas de explicação dessa ruptura são divergentes. Se o fracasso da antiguidade em alcançar o capitalismo moderno é um elemento comum nas análises de Marx e Weber; por outro lado, os argumentos utilizados por eles são distintos.

Marx delimita um corte qualitativo entre o mundo pré-capitalista e o mundo moderno, capitalista. A revolução contínua no processo de produção, a obsessão pelo aumento da produtividade e o aproveitamento da ciência para este fim são características do capitalismo. Weber define o 
capitalismo de forma diferente de Marx, não o delimitando ao mundo moderno, contudo caracteriza-o de forma diferente na Antiguidade.

Nos Grundrisse der Kritik der Politischen Ökonomie (Elementos fundamentais para a crítica da economia política), escrito entre outubro de 1857 e maio de 1858, mas somente publicados em 1939 e 1941, em Moscou, Marx, na "Introdução a uma crítica da economia política", ao delimitar seu objeto, a produção material, diferente de Adam Smith e Ricardo, afirma que sua preocupação é a produção dos indivíduos socialmente determinada. Em seu modelo das relações de produção de formações pré-capitalistas, no "Capítulo do Capital" dos Grundrisse, no item 'Formas que precederam a produção capitalista', Marx parte do pressuposto de que as sociedades pré-capitalistas diferem das sociedades capitalistas, porque naquelas o indivíduo se relaciona com as condições objetivas de seu trabalho como sua propriedade, configurando uma unidade natural do trabalho com seus pressupostos objetivos. Tal unidade é vista por Marx como uma relação espontânea - natural - e sua dissolução, que só é completada no capitalismo, é um processo histórico, no qual há uma transformação das relações do indivíduo com a comunidade, uma individualização, sendo a troca um dos agentes dessa individualização. Marx busca estabelecer, em sua análise das sociedades pré-capitalistas, as condições necessárias para a emergência do capital como relação social determinante em um modo de produção determinado. Marx não busca no passado as causas e efeitos inexoráveis para reconstruir uma história linear, como Bücher, mas compreender retroativamente os processos de mudança social que permitiram o presente surgir do modo como se apresenta (Turatti, 2011: 80).

A existência de um trabalho livre, transformado em mercadoria pronta para ser trocada por dinheiro para se reproduzir, é um pressuposto histórico fundamental da sociedade capitalista. Para que isso aconteça, é necessário que tenha se dissolvido toda uma série de formas econômicas em que o trabalhador não esteja separado das condições objetivas de produção. Estas condições de não separação se encontram em todas as formações econômicas pré-capitalistas. Eis um traço fundamental da separação entre as sociedades capitalistas e pré-capitalistas.

Portanto, de acordo com Marx, no mundo antigo não era possível se encontrar uma economia unificada em torno do capital, pois o mundo pré-capitalista se caracterizava por desenvolvimentos limitados e locais, múltiplos, paralelos e extremamente diversos. Apesar do capital realizar momentos de unificação, como nas economias dos povos comerciais, estes apareciam como entidades separadas do resto das comunidades, já que viviam nos poros, interstícios do mundo antigo. A economia agrária 
dos povos clássicos e a mercantil dos povos comerciais, fenícios e cartagineses, apareciam justapostas, separadas e não como partes de uma mesma economia integrada. Mesmo limitados, o processo de circulação de bens e o surgimento do valor de troca podem modificar a produção com uma ação desagregadora, mas, na antiguidade Clássica, isto ocorre sem que cheguem a provocar a derrubada das relações econômicas predominantes. Nas sociedades greco-romanas, mas não nas asiáticas, o processo de troca, apesar de separado da produção, tem efeitos parciais sobre a própria produção, cedendo lugar à conjunção parcial entre valor de troca e valor de uso, pois este aparece no início e no fim do processo: o dinheiro é um mediador da troca de produtos. Assim, o capital comercial aparece como um mediador entre extremos que ele não domina e entre pressupostos que não cria (Cardoso, 2011: 33-36).

Marx toma a antiguidade para mostrar que o mundo moderno é transitório e superável, pois a superioridade que a modernidade propala em relação ao mundo antigo é um engodo, posto que não conseguiu alcançar as suas promessas, como, por exemplo, a superação da fome, da ignorância e escassez. Superação em escala não significava superar a antiguidade em duração. Ao tomar a base material para a análise de todas as sociedades e procurar identificar as leis de desenvolvimento econômico em uma escala histórica, Marx, por meio dos distintos modos de produção, procurou ressaltar a imperfeição do capitalismo e sua suposição ilegítima de universalidade e atemporalidade. Organizado em torno de princípios diversos do capitalismo com diferenças nos valores e na mentalidade econômica, o mundo antigo tinha, no modo de organização do trabalho, o elemento central de sua distinção do mundo moderno. A exploração do trabalho livre pelos proprietários do capital era radicalmente diversa da lógica escravista, dominante no mundo antigo (Morley, 2009: 41-43). A escravidão era incompatível com o capitalismo, exceto como uma anomalia. Por outro lado, o trabalho livre teve pouca ou nenhuma influência na economia antiga. Portanto, não faz sentido falar de capitalismo ou capitalistas no mundo antigo.

O fenômeno do capitalismo esteve no centro das preocupações da Sociologia econômica de Max Weber, sendo a singularidade do Ocidente moderno, sua questão mais central, mas, diferente de Marx, sua esquematização de estruturas socioeconômicas comparativas não impede a possibilidade de formas de capitalismo anteriores à forma burguesa que emergiu depois da Renascença. A diversidade das causas e as distintas tendências típicas de orientação das atividades aquisitivas, que não cessavam de intervir no curso de seu desenvolvimento histórico, são os argumentos que o levaram a acreditar que não havia um capitalismo, mas 
capitalismos, daí não ser possível reduzi-lo a uma fórmula. Encontramonos diante do capitalismo, quando em "uma economia de produção a satisfação das necessidades de um grupo humano se faz por intermédio da empresa, pouco importando a natureza das necessidades a satisfazer" (Weber apud Freund, 1980: 127). Tais elementos constitutivos permitiram a Weber afirmar que houve embriões ou formas de capitalismo: ora aventureiro, ora mercantil, orientado para a guerra, para a política ou para a administração, na China, na Índia, na Babilônia, na Antiguidade Clássica e na Idade Média. Se àqueles traços, porém, forem acrescentados outros elementos constitutivos, por exemplo, a empresa capitalista racional, ou seja, aquela baseada no cálculo de capitais, associada às previsões de um mercado regular e à organização capitalista do trabalho (formalmente) livre, bem como uma distribuição de serviços orientada puramente pelos princípios da economia de troca, então estamos diante de um tipo particular de capitalismo: o capitalismo moderno ocidental. Em outras palavras, toda sociedade capitalista apresenta singularidades que não encontramos em outras sociedades do mesmo tipo. Daí a importância da distinção de Weber entre o mundo moderno, dominado pelo capitalismo racional e de mercado - racional e centrado nas oportunidades formalmente pacíficas do mercado; e o mundo antigo, com características do capitalismo politicamente orientado, definido como a exploração das oportunidades de lucro que surgem a partir do exercício do poder político, não estando totalmente ausentes alguns aspectos do capitalismo de mercado, mas não dominantes.

Não é no seu primeiro trabalho sobre história econômica da antiguidade, Die römische Agrargeschichte (História Agrária Romana), que Weber irá aprofundar seu conceito de capitalismo político e suas diferenças com o mundo moderno. Este trabalho, muito mais próximo dos modernistas, escrito em um momento em que Weber estava estreitamente associado a Mommsen, nos mostra que ele tinha assumido a compreensão convencional concernente à natureza do capitalismo moderno e anacronicamente projetou suas formas no passado para as condições da sociedade antiga. Weber está interessado em descobrir precisamente como instituições legais antigas vieram a reconhecer uma concepção de propriedade notavelmente próxima à nossa, a propriedade privada, que só se concretizou com o pleno desenvolvimento do imperialismo romano e as oportunidades econômicas que se abriram com a enorme expansão do chamado ager publicus. A propriedade fundiária, em geral, foi tratada como objeto de interesse econômico especulativo e, na visão de Weber, como um estrato capitalista emergente. O efeito completo de tudo isso foi a de permitir uma espécie de capitalismo agrário de enorme extensão no qual interesses capitalistas rapidamente vieram a dominar a vida 
econômica e os assuntos sociais em geral. Weber está mais preocupado em descrever e analisar as dimensões especificamente agrárias desta primeira forma de capitalismo, na qual os patriciados romanos, como um todo, eram os capitalistas em um sentido adequado do termo. Ele fala também de "métodos capitalistas", "um ethos capitalista", e ainda, ocasionalmente, "uma economia capitalista" (Love, 1991: 14-16). Apesar da divergência com a perspectiva de Marx, que não vê capitalismo no mundo antigo e, portanto, a impossibilidade de desenvolvimento do capital, Sérgio da Mata (2013) percebe neste trabalho uma dívida de Weber com a análise de Marx sobre a acumulação primitiva do capital na Inglaterra, no qual Weber tentava antever as tendências gerais do processo na Alemanha e propor políticas públicas para enfrentar o problema.

Se, neste trabalho, a influência de Monnsem é predominante, não há dúvida que em seu famoso artigo "Die sozialen Gründe des Untergangs der antiken Kultur" (As Causas Sociais do Declínio da Cultura Antiga"), publicado em 1896, Weber rompe com a perspectiva daquele trabalho e apresenta uma análise que é considerada por muitos como o texto de maior influência de Marx, $^{3}$ além de demonstrar simpatia pelo primitivismo, mas não compartilhar a opinião de que o oikos dominou toda a Antiguidade. Logo no início do texto, ele afirma que "pouco ou nada podemos aprender na História da Antiguidade que sirva para os problemas sociais de hoje" (Weber, 2013: 391). O declínio da cultura antiga tinha somente um interesse histórico. Por isso, deviam-se tornar claras as peculiaridades da estrutura social da Antiguidade.

Weber afirmou que a cultura antiga era, essencialmente, urbana. A cidade antiga trocava produtos da indústria urbana com os frutos da estreita orla agrícola circundante. Uma troca direta entre produtores e consumidores, sem necessidade de importação do exterior. O comércio internacional não afetava o ideal autárquico da cidade antiga, pois estava reduzido a artigos de grande valor - os objetos de luxo - com altos custos de transporte, interessando somente a uma fina camada constituída de

\footnotetext{
3 Em uma resenha do livro The Agrarian Sociology of Ancient Civilizations, Jonathan M. Wiener encontra vários pontos em comum entre o texto "Die sozialen Gründe des Untergangs der antiken Kultur" ("As Causas Sociais do Declínio da Cultura Antiga”) e a análise de Marx, como por exemplo a distinção de expansão quantitativa e transformação qualitativa de produção para o mercado. $\mathrm{O}$ autor chega a afirmar que a análise de Weber é notável porque carece de tudo o que consideramos de traços "weberianos" característicos. Em The Agrarian Sociology of Ancient Civilizations, o autor afirma que Weber usa o método marxista ao tomar como ponto de partida para análise de uma formação social o modo no qual a classe dominante extrai o trabalho excedente oriundo da classe dominada (Wiener, 1982: 389-401).
} 
possuidores. Diante de tal quadro, Weber (2013: 392) afirma: "um comércio deste tipo não se pode comparar em nada com o moderno". Eis um contraponto eloquente à perspectiva modernista.

Neste ensaio, Weber atribui importância causal decisiva para a infraestrutura econômica. Acerca do impacto econômico da escravidão, Weber faz um empréstimo mais inventivo de oposição base/superestrutura de Marx. Define a cultura antiga como escravista, caracterizada por uma progressiva acumulação de homens, adquiridos a um baixo preço, derivado do caráter incessante das guerras da Antiguidade. Isso impediu o progresso técnico da cultura antiga e concentrou nas mãos dos proprietários de escravos a produção de um excedente, produzido pelo trabalho escravo para a venda no mercado, além da produção interna para o provimento do próprio oikos. Eis como Weber percebeu a contradição da economia antiga: o crescimento do quartel de escravos e a escala crescente de produção para o mercado, motivado pelas necessidades das camadas superiores, não fomentaram o desenvolvimento do domínio local da economia urbana com base na produção de encomendas para clientes e do comércio local, tal como se deu na Idade Média. No momento em que as guerras de conquista cessaram e, consequentemente, o fluxo de mão de obra escrava, o sistema entrou em colapso, pois o mercado da cidade, alimentado pela produção escravista e não pela mão de obra livre, perdeu seu elo com as grandes propriedades, não havendo mais a troca de gêneros e de trabalho com o campo circundante. O resultado disso foi o crescimento da economia natural, com o escravo, como vassalo no seio da família independente, fora do oikos, possibilitando ao senhor manter sua provisão de força de trabalho, sem a necessidade de conservação da mão de obra escrava. Uma transformação nas camadas mais inferiores da sociedade, pois a família e a propriedade pessoal lhes são restituídas (Weber, 2013: 400). Assim, a queda do Império romano é a consequência política do desaparecimento gradual do comércio e do conseguinte crescimento da economia natural. O fim de uma superestrutura política de um regime de economia monetária, que não mais se ajustava à infraestrutura econômica, dominado agora por um regime de economia natural.

É difícil evitar a conclusão de que, nesse ensaio, o modo de explicação de Weber é quase indistinguível daquele do assim chamado materialismo histórico. A partir da exegese acima, está claro que Weber coloca uma enorme importância em um único fator material: ou seja, uma oferta adequada dos escravos baratos como a base de civilização antiga. Todos os outros elementos na descrição - a crescente ineficácia do exército, a burocratização do estado imperial tardio, a mudança de vida cultural das 
cidades para o campo - parecem ganhar a sua gravidade específica da sua ligação com o fator da escravidão. Mas, apesar da semelhança superficial ao determinismo econômico, Weber utiliza perspectivas que, de fato, vão além de uma abordagem monocausal, pois ele fornece um modelo completamente diferente da base socioeconômica da antiga sociedade do que aquela de Marx. Na verdade, ele analisa uma vasta gama de fenômenos, como as pré-condições política e militar da escravidão, a estrutura da vida urbana, as lutas dos ricos e pobres sobre propriedade latifundiária, a natureza do oikos e as formas da família, a formação de um setor de mercado na interseç̧ão das esferas urbana e rural, o comércio internacional à base de artigos de luxo e outros aspectos. No ensaio de Weber, apesar de suas tendências reducionistas, percebe-se uma variada série de tipos ideais - economia urbana, economia de oikos, economia na cidade medieval, exército feudal, a cidade-estado, a cidade comercial costeira, economia de plantation, economia natural e assim por diante - e as relações, transições e misturas causais. Assim, revela-se uma prática que desmente a sua alegação meta-histórica de ter demonstrado a causa "econômica" do colapso da civilização antiga, pois suas explicações envolvem diversos dados sociais e políticos (Love, 1991: 22-25).

A descontinuidade entre o mundo antigo e o moderno, presente nas análises de Marx e Weber, distanciou-se não só dos economistas do século XVIII e XIX, mas também das explicações dos modernistas e primitivistas, pois havia entre estes uma convergência em relação à derivação genealógica entre o fim do mundo antigo e o mundo moderno, mais acentuada entre os modernistas, que reduzem a distância entre os dois mundos apenas a um capricho cronológico, porém não ausente entre os primitivistas, apesar de atenuada, por uma maior ênfase nas diferenças decorrentes dos lentos progressos acumulados ao longo de um milênio.

$\mathrm{Na}$ verdade, esta descontinuidade é provavelmente uma das maiores contribuições desses dois pensadores aos estudos da História Antiga, com reflexos na historiografia atual. Aldo Schiavone, por exemplo, reafirma a indissociabilidade entre a economia romana e a da modernidade europeia e atlântica, presentes em dois mundos totalmente distintos, separados de forma qualitativamente diferentes, caracterizados por estratos de mentalidade, de hábitos, de comportamentos, de condições materiais e culturais, cujas linhas formativas divergem drasticamente (Schiavone, 2005: 246).

Schiavone não só reafirma essa descontinuidade, como também procura explicar seus motivos e razões, deixando-nos uma sensação de que as análises de Marx e Weber são complementares e abrem um canteiro de pesquisa fértil para a História Social. Ao tomar como hipótese de que não 
houve continuidade entre o fim do Império Romano e o mundo moderno, Schiavone levanta duas questões de fundo que estiveram presentes nas reflexões de Marx e Weber: o caráter escravista e os obstáculos tecnológicos do mundo antigo clássico como elementos diferenciadores desses dois mundos. O autor explora esses temas partindo do pressuposto de que o mundo greco-romano era caracterizado pelo seguinte tripé: a difusão da escravidão-mercadoria, a desvalorização do trabalho e da materialidade transformadora e o constante déficit mecânico nos processos produtivos. A repulsa do trabalho naquela sociedade remonta à mentalidade individualista que se afirmou nas aristocracias e cidades-estados gregas e romanas. Nesse mundo, não era a materialidade da ação, da produção, o que era ressaltado, mas o favorecimento da natureza e a liberdade civil e política. A pequena propriedade agrária e sua exploração direta eram o estatuto político da cidadania. Esta forma econômica materializada em uma instituição política, a cidade-estado, formava o quadro cultural e mental do mundo greco-romano. Concomitantemente, a organização social influenciou as formas e os modos de se pensar a artificialidade transformadora, isto é, a atitude daquela sociedade em relação à natureza e seus fenômenos. Havia um abismo entre conhecimento e transformação da natureza. O mundo antigo não conseguiu ultrapassar as barreiras mentais da metafísica para reconhecer o mundo sensível como território da razão, controlado pela verificação experimental. Não houve conexão entre o conhecimento científico e transformação do ambiente externo, ou entre ciência e poder. O equilíbrio estático da relação tecnológica entre sociedade e natureza, sem possibilidades de mudança, sem a ambição transformadora tão característica do mundo moderno, era um traço marcante do caráter eminentemente rural da sociedade antiga (Schiavone, 2005: 197-219).

Indo ao coração dos pressupostos de Marx e Weber, Schiavone, de forma mais fundamentada, contesta-os, afirmando que a escravidão não foi responsável pelo atraso tecnológico, pela desconexão entre produção e máquina, pois essa remonta a condições mais longínquas, anteriores à escravidão, apesar da presença maciça de escravos suprir, em parte, os efeitos do déficit mecânico, garantindo reserva de energia barata e uma economia voltada para a troca, circulação mercantil, desenvolvimento urbano. Portanto, o trabalho escravo não era ineficiente, nem "irracionalmente" organizado, mas não poderia impulsionar uma transformação capitalista, pois era simétrico aos valores aristocráticos que, por sua vez, não cultivavam uma visão mecânica e quantitativa da natureza. $\mathrm{O}$ trabalho escravo e o trabalho livre apresentam-se como dois formalismos opostos: o trabalho escravo, baseado no status, define-se pela relação pessoal de dependência, exerce a sua força a partir do domínio 
pessoal e impede a separação entre a personalidade do trabalhador e a venda da força de trabalho em detrimento de uma sujeição total do trabalhador; enquanto o trabalho livre, baseado no contrato, define-se pela troca entre dois sujeitos juridicamente iguais, agindo em favor do capital e do mercado, permitindo uma nova conexão entre subjetividade e trabalho produtivo, algo inimaginável na Antiguidade (Schiavone, 2005: 197-219).

Assim, apesar de algumas características semelhantes entre o mundo antigo e o moderno: vida urbana, comércio, divisão do trabalho, etc., não há nenhuma derivação direta do mundo antigo, pois a circulação comercial, por exemplo, entre estes mundos, foi intrinsicamente diferente, tendo no máximo a possibilidade de se afirmar algumas simetrias funcionais que conduzem a similaridades tipológicas. O Ocidente moderno foi determinado por aquisições mentais e sociais totalmente estranhas ao mundo greco-romano, além de uma longa reapropriação civil do trabalho e a invenção de uma relação entre trabalho dependente e liberdade pessoal, além de uma reconquista de uma dimensão física da natureza, como condição de uma aliança entre inteligência e produtividade. Daí a importância de trabalhos como A Ética Protestante e o Espírito do Capitalismo de Weber e "Assim Chamada Acumulação Primitiva" do livro O Capital de Marx, reflexões que demarcam com muita clareza as características do mundo moderno, produtos de transformações econômicas e mentais que não remetem ao mundo antigo.

\section{O Ocidente e o Oriente: Uma Dicotomia advinda de uma Visão Eurocêntrica}

A descontinuidade entre o mundo antigo e o Ocidente moderno é uma contribuição relevante de Marx e Weber para o entendimento do mundo moderno e da Antiguidade. Contudo, esses pensadores também foram responsáveis por paradigmas que reforçaram a visão eurocêntrica acerca do mundo antigo ao afirmarem que as raízes culturais e políticas do Ocidente moderno repousam na Antiguidade Clássica, apesar da ruptura entre o antigo e o moderno. Neste sentido, forjaram uma tradição de pensamento em que as sociedades antigas do Oriente eram muito diferentes das sociedades do mundo greco-romano, marcadas pela ausência de diversos traços sociais, econômicos e políticos presentes no Ocidente. Um dos argumentos principais dessas diferenças era a singularidade do Ocidente, sem conexão com outras sociedades asiáticas e sem conexão com períodos anteriores. A tradição eurocêntrica que Marx e Weber se encontram defende o paradigma de que a Antiguidade 
Clássica teria sido fundadora de aspectos relacionados com a política democracia -, cultura - letramento e artes - e no campo da organização social, a propriedade privada.

Da mesma forma que Marx rejeitou a hipótese dos economistas ingleses clássicos em relação às continuidades entre a Antiguidade Clássica e o mundo moderno, ele também deixou-se conduzir pela constatação do caráter imóvel em que se encontraria a Ásia: uma economia agrícola e uma classe camponesa servil, dominada por um poder despótico. Por essas razões, esses povos jamais poderiam chegar ao capitalismo, pois o principal traço dessa "singularidade asiática", nas palavras de Goody (2000: 12), é um tipo oriental estagnante de sociedade.

A unidade entre a comunidade e a propriedade ou o comportamento em relação às condições objetivas da produção como existência natural tem sua realidade viva em um "modo de produção" determinado, que se traduz como comportamento dos indivíduos uns em relação aos outros, ou como seu comportamento determinado em relação à natureza inorgânica. O conceito de modo de produção é uma articulação historicamente dada às forças produtivas e às relações de produção que lhes correspondem. Muitos dos equívocos e confusões das interpretações acerca do conceito marxiano de modo de produção advêm da leitura do Prefácio para A contribuição à crítica da Economia Política, escrito em 1859, e publicado no mesmo ano, no qual Marx designa na formação econômica da sociedade o modo de produção asiático, o antigo, o feudal e o moderno burguês, sendo este a última forma antagônica do processo social de produção (Marx, 2008: 48).

A propriedade originalmente significa o comportamento do ser humano em relação às suas condições naturais de produção como pertencentes a ele, como condições pressupostas com a sua própria existência. O ser humano se relaciona com as condições naturais de produção de duas formas: primeiro como membro de uma comunidade, que em sua forma original é um sistema tribal, e segundo por seu comportamento em relação à terra, mediado pela comunidade, como propriedade comunitária sua e como posse individual. A propriedade significa, portanto, pertencer a uma comunidade, com existência subjetiva e objetiva dentro dela (Marx, 2011: 651-652). A propriedade é o comportamento do indivíduo (que se reproduz) que trabalha (que produz) em relação às condições de sua produção ou reprodução como condições que são suas. Por isso, a propriedade terá formas distintas, segundo as condições dessa produção, em um modo de produção determinado. Nas distintas formas de propriedade nas sociedades précapitalistas, a finalidade do trabalho não é a criação de valor, mas a 
conservação do proprietário singular e de sua família, bem como da comunidade como um todo.

$\mathrm{Na}$ forma oriental, a propriedade só existe como propriedade comunitária, o membro individual enquanto tal é somente "possuidor", hereditário ou não, de uma parte particular como membro imediato da comunidade. Existe só comunidade coletiva e só posse privada, sendo modificada historicamente de forma muito desigual, dependendo se o trabalho é realizado isoladamente pelo possuidor privado ou determinado pela comunidade ou pela unidade pairando acima da comunidade particular, que se situa acima de todas essas pequenas comunidades, aparecendo como o proprietário supremo ou o único proprietário, o déspota, o proprietário real e o pressuposto real da propriedade comunitária. Com isso, o produto excedente pertence à coletividade, extraído por meio do tributo ou no trabalho coletivo para a glorificação da unidade, em parte do déspota real, em parte do ente imaginário do clã, do deus, determinado legalmente em razão da apropriação real pelo trabalho (Marx, 2011: 628-630).

Na segunda forma de propriedade, relacionada com as sociedades grecoromanas, o solo é ocupado pela comunidade, é solo romano (Marx se voltou prioritariamente para a sociedade romana); uma parte continua sendo da comunidade, outra parte é repartida e cada parcela do solo é romana pelo fato de ser a propriedade privada, o domínio de um cidadão, a cota que lhe pertence. Ser membro da comunidade continua sendo aqui pressuposto para a apropriação de terras, mas, como membro da comunidade, o indivíduo singular é proprietário privado. Como a comunidade (Estado) é aqui o pressuposto da propriedade da terra - i.e., da relação do sujeito trabalhador com os pressupostos naturais do trabalho como pertencentes a ele -, esse pertencimento, no entanto, é mediado pelo seu ser como membro do Estado (Marx, 2011: 635-636).

Segundo Marx, a história da antiguidade clássica é a história das cidades fundadas na propriedade da terra e na agricultura, é a sede já constituída das pessoas do campo. O campo aparece como território da cidade e a guerra constitui a grande tarefa conjunta e a comunidade, composta de famílias, organiza-se de início como comunidade guerreira, sendo essa uma das condições de sua existência como proprietária, concentrada na cidade. A propriedade comunitária - como propriedade do Estado, ager publicus - é separada aqui da propriedade privada. Nas formações asiáticas propriamente ditas, há uma espécie de unidade indiferente de cidade e campo e as cidades formaram-se, ao lado desses povoados, apenas em pontos especialmente favoráveis ao comércio exterior; ou onde 
o chefe de Estado e seus sátrapas trocavam sua renda (produto excedente) por trabalho (Marx, 2011: 631-633).

Além disso, as formações greco-romanas caracterizam-se pela preservação da igualdade entre seus camponeses autossuficientes livres e o trabalho próprio como condição da continuidade de sua propriedade. A aquisição de riqueza não é o objetivo central dos indivíduos, mas a autoconservação, sua própria reprodução como membro da comunidade, como proprietário do lote de terra e, nessa qualidade, como um membro da comuna, como camponeses autossuficientes, cujo tempo excedente pertence justamente à comuna, ao serviço militar.

Tanto no Ocidente como no Oriente, a propriedade da terra e a agricultura constituem a base da ordem econômica, contudo a forma asiática se mantém com mais tenacidade, resistindo mais as mudanças históricas em virtude da unidade entre agricultura e manufatura e pela ausência de autonomia do indivíduo em relação à comunidade. No Ocidente, onde já existe a separação entre os membros da comunidade como proprietários privados de si mesmos como comunidade urbana e proprietários de território urbano, já estão dadas as condições pelas quais o indivíduo singular pode "perder" sua propriedade, i.e., a relação dupla que o torna cidadão igual aos demais, membro da comunidade e que o torna "proprietário". Na forma oriental, essa "perda" dificilmente é possível, exceto por influências completamente externas, uma vez que o membro singular da comunidade jamais entra em uma relação livre com ela e pela qual ele possa perder seu vínculo (objetivo, econômico com a comunidade). Ele é enraizado. Por outro lado, isso depende também da associação entre manufatura e agricultura, entre cidade (o povoado) e campo. Entre os antigos, principalmente os romanos, a manufatura já aparece como corrupção (negócio de libertos, "clientes", estrangeiros) etc. Esse desenvolvimento do trabalho produtivo, que necessariamente resulta do intercâmbio com estrangeiros, escravos, do desejo de trocar o produto excedente etc., dissolve o modo de produção sobre o qual a comunidade se baseia (Marx, 2011: 655-656).

Em Agrarverhältnisse im Altertum, inicialmente escrito em 1897, reescrito no ano seguinte e, finalmente, publicado em 1908, traduzido para o inglês, em 1909, sob o título de The Agrarian Aociology of Ancient Civilizations, após seu colapso nervoso, Weber apresenta um panorama geral das quatro grandes civilizações do mundo antigo. Aqui, Weber cede às críticas dos historiadores modernistas ao limitar a importância do oikos na economia do mundo antigo e ao seccionar a Antiguidade em zonas socioeconômicas e culturais distintas, em civilizações, em que cada uma passou por formas específicas de desenvolvimento. Finalmente, Weber dá 
um passo além dos primitivistas, ao separar a pólis clássica da economia do oikos, associando o declínio do oikos ao desenvolvimento da pólis e, posteriormente, ao capitalismo. O oikos tem um papel de destaque na Grécia, nos estágios iniciais, no Oriente Próximo e, no final da Antiguidade, no Império Romano. A importância do oikos está associada à realeza no Ocidente e Oriente, sendo, no entanto, interrompida no Ocidente com o surgimento da pólis aristocrática e a abolição da realeza. A historicidade desses estágios históricos dissolve os conceitos unitários elaborados por Bücher, em que a visão linear é substituída por uma visão cíclica, diferente daquela de Meyer, que relacionava períodos da Antiguidade com períodos da Idade Moderna de forma homóloga.

Weber, aqui, já utilizava o oikos como um tipo ideal e procurava perceber em seus estudos históricos, as civilizações antigas que se aproximavam ou se distanciavam do seu modelo. Em The Agrarian Sociology of Ancient Civilizations, Weber aponta o desenvolvimento de um particularismo militar urbano da pólis grega como o principal elemento diferenciador das monarquias burocráticas do Oriente Próximo. Em contraste com o crescimento de um séquito real extremamente dependente do rei no Oriente, na Grécia, assistiu-se a uma dominação dos séquitos reais e, consequentemente, ao desenvolvimento de um exército recrutado entre os pequenos fazendeiros rurais que podiam prover seu próprio equipamento militar. Esta particularidade levou ao enfraquecimento do poder real e à ausência de burocracias reais e de grandes Estados, traço marcante do desenvolvimento das monarquias orientais (Weber, 2013: 157-158).

A insistência em universalizar categorias como capitalismo, burocracia, feudalismo e mesmo "Ocidente" surge em The Agrarian Sociology of Ancient Civilizations pela comparação entre as póleis greco-romanas e as formações do Oriente Próximo. O capitalismo se tornou dominante no Ocidente, na medida em que o político assume um papel preponderante na análise das estruturas econômicas. O rompimento com a realeza no Ocidente, algo que não acontece no Oriente, abre caminho para o surgimento da pólis e do capitalismo. É só nas cidades-estados que se desenvolvem novas formas de regra política, interação econômica ou legitimação ideológica em entidades geopolíticas claramente diferenciadas. Portanto, a pólis é um elemento causal influente que afasta as sociedades gregas e romanas do modelo do oikos.

Weber também propõe uma série de estágios de desenvolvimento para o Oriente Próximo, cujos tipos - da fortaleza real aos Estados autoritários litúrgicos ou reinos burocráticos - são formas de organização política em que a burocracia estatal, ao mesmo tempo em que reprime o capitalismo, 
acentua e consolida o papel do oikos real, monopólio daquele que detém o poder político, ideológico e econômico e inclui o exército, a burocracia e o templo. Weber reemprega o oikos, diferente de Rodbertus e Bücher - que o definem como a principal instituição da civilização greco-romana como predominante nas realezas burocráticas orientais e como um obstáculo ao surgimento da pólis e desenvolvimento do capitalismo e feudalismo. A mudança de foco é o papel institucional do Estado - as realezas burocráticas - que determina o curso das transações econômicas em detrimento das forças mercantis.

Em algumas conferências, proferidas em 1909, ele teceu críticas à burocracia prussiana de forma muito parecida às críticas feitas em The Agrarian Sociology of Ancient Civilizations às sociedades do Antigo Oriente Próximo e mesmo à Roma imperial. A Grã-Bretanha, os Estados Unidos e a França forneciam, naquele momento, os pontos comparativos positivos. Apesar de criticar o ideal burocrático de vida, Weber preferia a burocratização da sociedade capitalista moderna à paz e segurança da burocracia total prometida pelo socialismo (Nafissi, 2005: 122). Na época de The Agrarian Sociology of Ancient Civilizations, Weber toma como parâmetros comparativos a burocracia prussiana e o socialismo e não as sociedades capitalistas modernas.

Entre 1911-1913, Weber escreveu um outro artigo no qual tece considerações sobre o mundo antigo intitulado Die nichtlegitime herrschaft. Typologie der stadte (A dominação não-legítima - A tipologia das cidades), publicado em Wirtschaft und Gesellschaft (Economia e Sociedade). Este trabalho tem como eixo comparativo não somente o Oriente e o Ocidente, mas, também, o capitalismo antigo e o moderno. A linha de continuidade entre The Agrarian Sociology of Ancient Civilizations e "A dominação nãolegítima - A tipologia das cidades" é o estudo dos fundamentos da cidade associados ao desenvolvimento também peculiar ao Ocidente. Contudo, neste livro, Weber deixa de ver as sociedades antigas sob uma perspectiva de um historiador da Antiguidade, passando a vê-las, prioritariamente, como elementos comparativos de referência para uma melhor compreensão de peculiaridades do capitalismo moderno, da sua emergência e de seu futuro. Por isso, nele encontramos elementos da Sociologia de Weber pouco desenvolvidos no primeiro livro, como dominação estamental, patriarcalismo, carisma, racionalidade e irracionalidade.

Em "A dominação não-legítima - A tipologia das cidades", o autor enfatiza o papel da esfera política sobre o tipo de capitalismo dominante no mundo antigo. Diferentemente da racionalidade da produção capitalista, as possibilidades aquisitivas no mundo antigo direcionavam- 
se para "fornecimentos do Estado, [...], para a expansão política e conquista de escravos, terras, tributos e privilégios para a aquisição de terras e empréstimos sobre estas, além do comércio e fornecimento nas cidades submetidas" (Weber, 2004: 500). Assim, Weber procura demonstrar, particularmente em "A dominação não-legítima - A tipologia das cidades", que a forma de dominação política em que preponderavam os valores (ethos) de um estamento guerreiro criava obstáculos ao desenvolvimento das atividades econômicas racionais. Esta ideia não está ausente em The Agrarian Sociology of Ancient Civilizations, contudo, aqui, Weber procura acentuar o papel pioneiro da pólis na formação de um tipo de capitalismo em contraposição ao do Oriente, como um estágio de desenvolvimento histórico "avançado", enquanto, em "A dominação nãolegítima. A tipologia das cidades", o capitalismo representa um momento ainda embrionário em relação ao capitalismo moderno.

Apesar de rejeitar o marxismo como uma ideologia política, a influência de Marx nos trabalhos de Weber sobre a Antiguidade, em particular sobre a economia antiga, se encontra na base teórica de seus argumentos na definição do problema do desenvolvimento capitalista. Além disso, a ausência do desenvolvimento da propriedade privada e do capitalismo no Oriente antigo, vista como uma especificidade do Ocidente, uma justificativa para o "atraso" do Oriente em relação ao Ocidente, é compartilhada por Marx e Weber, e, posteriormente, seguida por Polanyi e Finley, com argumentos diferenciados. Eis uma perspectiva dominante nos séculos XIX e XX, que procurava as origens da cultura europeia e ocidental nas sociedades greco-romanas, mas que atualmente vem sendo fortemente questionada por estudiosos, historiadores e antropólogos, que ressaltam aspectos comuns e interações, em detrimento das particularidades e isolamento do mundo clássico.

Em seu estudo sobre as civilizações antigas Weber procura reconciliar duas suposições sobre o capitalismo e a antiguidade que são, à primeira vista, contraditórias. De acordo com Love (1991: 32), ele quer se opor a visão de que o capitalismo é específico do mundo moderno, modelando uma definição suficientemente ampla do capitalismo (não baseada no contrato de trabalho) que permita a inclusão de certos tipos de atividade encontrada na antiguidade e em outros lugares. A exploração de escravos é tida como uma "atividade capitalista", posto que, é uma atividade com fins lucrativos e que envolve o dinheiro. Por outro lado, Weber também está preocupado em explorar a diferença da economia antiga do capitalismo moderno; embora não seguindo as mesmas linhas diretrizes da esquematização marxista. Portanto, ao criar uma linha divisória entre o mundo antigo e o mundo moderno por meio de tipos capitalismos 
diferentes, Weber procura conciliar os pontos de vista de Mommsen e Meyer, ao enfatizar o papel do capital e a adequabilidade de analogias modernas, com a perspectiva de Rodbertus e Bücher, destacando a singularidade da antiguidade e a importância do oikos e a autarquia urbana. Segundo Love, o resultado é contraditório, porém, apesar de não totalmente satisfatório, acreditamos que o esforço de Weber representava o anseio de superar a dicotomia simplificante do debate entre primitivistas e modernistas.

Portanto, tanto Marx quanto Weber atribuem à Antiguidade Clássica um papel "fundador" à cultura Ocidental. No caso de Weber, pela presença do capitalismo e da pólis, e no de Marx, pela presença da propriedade privada e da democracia. Contudo essa perspectiva eurocêntrica, muito presente no século XIX, tem sido fortemente combatida na historiografia atual. ${ }^{4}$ Os contatos entre as civilizações do mundo greco-romano e do Antigo Oriente Próximo com trocas econômicas e culturais têm sido cada vez mais assinalados por trabalhos atuais. Na verdade, a preocupação central de Marx e Weber pelo capitalismo, sua origem e superação, no caso de Marx, explica, em grande parte, este caráter eurocêntrico de seus modelos.

\section{Conclusão}

Karl Marx e Max Weber estão preocupados em seus modelos científicos com uma concepção do que era específico do mundo moderno, em particular, o capitalismo ou um tipo de capitalismo. Os dois autores ofereceram duas consistentes explicações históricas sobre as origens, desenvolvimento e significado do capitalismo. De acordo com ColliotThélène (1995: 51-63), Marx, preocupado com uma ciência da realidade, trata de indivíduos reais, de sua ação e de suas condições materiais de vida. A realidade se apresenta já estruturada pelas categorias que orientam, desde o início, o caminho da investigação. As noções de forças produtivas, relações sociais, estruturas políticas e representações dão a essa realidade uma estrutura hierarquizada, fixada pela ordem das determinações causais, elementos presentes na sociologia weberiana, preocupada com as conexões causais, ligadas por práticas, estruturas e formas de representações. Neste trabalho, ao investigarmos as reflexões desses pensadores acerca da economia e sociedades antigas, concluímos que a oposição entre o monismo econômico e o pluralismo causal weberiano não chega a ser uma divergência tão aguda, apesar de

\footnotetext{
${ }^{4}$ Ver Goody (2008).
} 
presente, "quando se toma um projeto comum de compreensão da história que tem como centro de interesse a atividade social dos homens" (Colliot-Thélène, 1995: 64).

A acentuação das diferenças entre esses dois autores, de fato reais, pois Marx oferece uma narrativa da transformação histórica ligada a uma agenda política explícita da revolução, enquanto Weber foi cético e mesmo hostil a essa agenda, não pode ocultar o quanto Weber é devedor dos diversos insights levantados por Marx. A diferenciação institucional entre a economia e a política, tão cara a Weber, e posteriormente a Polanyi, não encontra afinidade com a ideia marxista de que só é possível arrancar o excedente do camponês por meio de uma coerção extra econômica nas sociedades pré-capitalistas. Em um momento de forte influência do pós-modernismo, as teorias de Marx e Weber estão comprometidas com a explicação de processos históricos de grande escala, com as generalizações teóricas com as quais as explicações particulares sejam inteligíveis e com a afirmação explícita de seus pressupostos teóricos, de modo que possam ser submetidos a uma análise crítica e avaliação empírica. Portanto, mesmo explicitando os limites da análise desses dois autores, o diálogo com estes dois programas de pesquisa ainda é muito frutífero para a historiografia atual, como por exemplo, o trabalho de Schiavone.

\section{Referências Bibliográficas}

BÜCHER, K. Études d'histoire et d'economie politique. Bruxelles; Paris: Henri Lamertin Éditeur; Felix Alcan Éditeur, 1901.

CARDOSO, C. F. S. Marx e Engels: história e economia política. Aspectos gerais e considerações sobre um tema específico, relativo à antiguidade clássica: a circulação de mercadorias. In: CARVALHO, A. G. A Economia Antiga: História e Historiografia. Vitória da Conquista: Edições UESB, 2011. p. 13-38.

CARVAlHO, A. G. (Org.) A Economia Antiga: História e Historiografia. Vitória da Conquista: Edições UESB, 2011.

COLLIOT-THÉLÈNE, C. Max Weber e a história. São Paulo: Brasiliense, 1995.

FREUND, J. Sociologia de Max Weber. Forense Universitária: Rio de Janeiro, 1980. 
GOODY, J. O Oriente no Ocidente. Algés: Difel, 2000.

O Roubo da História. Como os europeus se apropriaram das ideias e invenções do Oriente. São Paulo: Contexto, 2008.

LOVE, J. R. Antiquity and Capitalism. Max Weber and the sociological foundations of Roman civilization. London; New York: Routledge, 1991.

MARX, K. A ideologia alemã. Lisboa; São Paulo: Editorial Presença; Martins Fontes, 1965.

. Grundrisse. São Paulo: Boitempo, 2011.

Prefácio à contribuição à crítica da economia política. In:

A contribuição à crítica da economia política. Tradução de Florestan Fernandes. 2. ed. São Paulo: Editora Expressão Popular, 2008. p. 45-50.

MATA, S. A fascinação weberiana. Belo Horizonte: Editora Fino Traço, 2013.

MEYER, E. El historiador y la historia antigua. Estudios sobre la teoría de la Historia y la Historia económica y política de la Antigüedad. México; Buenos Aires: Fondo de cultura económica, 1955.

MORLEY, N. Antiquity and Modernity. Oxford: Wiley- Blackwell. 2009.

NAFISSI, M. Ancient Athens \& Modern Ideology. Value, theory \& evidence in historical sciences. Max Weber, Karl Polanyi \& Moses Finley. London: Institute of classical studies, 2005.

Classe, engaste (embeddedness) e a modernidade da Atenas Antiga. In. CARVALHO, A. G. (Org.) A Economia Antiga: História e Historiografia. Vitória da Conquista: Edições UESB, 2011. p. 123-165.

SCHIAVONE, A. Uma história rompida. Roma antiga e o Ocidente moderno. Tradução de Fábio Duarte Joly. São Paulo: Edusp, 2005.

TURATTI, M. C. M. Antropologia, economia e marxismo. São Paulo: Alameda, 2011.

WEBER, M. Economia e Sociedade: Fundamentos da sociologia compreensiva. Tradução de Regis Barbosa e Karen Elsabe Barbosa. 4. ed. Brasília: UnB, 2004. 2v.

The Agrarian sociology of ancient civilizations. Tradução de R. I. FRANK. London; New York: Verso, 2013. 
WIENER, J. Max Weber's Marxism: Theory and Method in 'The agrarian sociology of ancient civilizations". Theory and Society, v. 11, n. 3, 1982, p. 389-401. 